\title{
The Importance of Highly Engaged School- University Partnerships in Widening Participation Outreach
}

\author{
Nadine Zacharias \\ Swinburne University of Technology, Australia \\ Geoffrey Mitchell \\ Queensland Department of Education, Australia
}

\begin{abstract}
In Australia, there has been a sustained investment in widening participation activities by the federal government through the Higher Education Participation and Partnership Program (HEPPP) and a sustained effort by universities and their partner schools to create high-quality widening participation programs. However, there is limited longitudinal evidence on if and how these widening participation activities influence the application rates to university by school leavers from low socio-economic status (SES) backgrounds. This article draws on a large mixed-methods study which aimed to investigate differences in university application rates between students from low SES backgrounds in urban versus rural, regional and remote (RRR) schools in Queensland. The research found that widening participation programs had a positive and statistically significant influence on application rates to university in highly engaged schools. We propose the concept of a virtuous circle of sustained widening participation activity to explain the positive results in highly engaged schools.
\end{abstract}

Keywords: Widening participation; HEPPP; low socio-economic status; regional students; secondary education.

\section{Introduction}

In 2010, the Australian Government established the Higher Education Participation and Partnership Program (HEPPP) which injected substantial amounts of new funding into the university sector to improve participation of students from low socioeconomic status (SES) backgrounds in higher education (Australian Department of Education, Employment and Workplace Relations [DEEWR], 2009). This included sustained partnership activities between universities and key stakeholders, especially schools, to widen participation to higher education. Initially, dedicated partnership funding was provided by the HEPPP as a universal institutional allocation and through a competitive grant process. Tied partnership funding was abolished in 2014 and universities have funded any partnership activities through their general institutional HEPPP allocation since 2015.

Despite this significant and long-term investment in widening participation initiatives in Australia, and notable improvements in the participation rate of students from low SES backgrounds and other equity cohorts since 2010 (Koshy, 2017), there is little published evidence for a link between widening participation programs and subsequent university application and enrolment behaviour through longitudinal evaluations. Most studies focus instead on the short-term impact of particular programs on interest or intention to go to university or other post-school options (Bennett et al., 2015). Two studies that have attempted to establish correlations between ongoing widening participation activities and changes to university applications 
rates, the evaluation of the 'Bridges to Higher Education' project by KPMG (2015) and the evaluation of the 'Aspire UWA' widening participation program by Skene, Pollard and House (2016), have shown mixed results. Neither has been able to prove statistically significant relationships between widening participation programs and application rates, due to the short time-frame of the evaluation or study design.

The current state of research in Australia was summarised in the comprehensive evaluation of the HEPPP conducted by ACIL Allen Consulting (2017): “Although establishing causal links for interventions in education policy is difficult, evidence where available often shows increased aspirations and in some cases increased applications and enrolments to higher education" (p.58). Moreover, existing research has identified several factors which characterise effective widening participation programs (Cupitt et al., 2016; Gale et al., 2010; KMPG, 2015). However, these do not explain the processes by which widening participation programs influence student decision making about post-school options, and subsequent application behaviour.

There are also no ready-made solutions in the international literature. Evaluation of the long-running and large-scale 'Aimhigher' widening participation program in England by Passy and Morris (2010) struggled to find a clear association between participation in Aimhigher activities and improvements in aspiration, attainment and progression to higher education. The authors commented on the difficulty of proving a causal relationship in a context where there were multiple simultaneous factors impacting on student outcomes, and also where the number of participants in any one activity may be too small to establish statistical significance. Quantitative data alone were unable to establish associations for the way in which programs impact on students. Passy and Morris (2010) stated:

\footnotetext{
Much of the evidence provided showed an association between participation in Aimhigher activities and increased attainment and progression but, at the same time, offered little or no discussion of the processes through which Aimhigher might be impacting on participants' outcomes (p.15).
}

This article attempts to address the challenge articulated by Passy and Morris (2010) to identify the process and factors which shape student application behaviour through a mixed methods design. We draw on a larger study funded by a HEPPP National Priority Pool grant which used a unique longitudinal data set available in Queensland and triangulated the results of statistical analyses with qualitative results from case studies of nine schools in low SES communities involved in activities delivered by the Queensland Widening Tertiary Participation Consortium.

The Queensland Consortium received a large competitive HEPPP grant in 2011 (AUD\$15.6m over three years) to implement a state-wide collaboration which targeted Year 6 -12 students in state and non-state schools in low SES communities to improve students' understanding of post-school options and preparation and aspiration for higher education. Despite this coordinated effort by all public universities in Queensland to deliver similar widening participation activities in low SES schools across the state, a divergent pattern in application rates to university was observed in urban versus rural, regional and remote (RRR) schools. Application rates from urban low SES communities increased while application rates from RRR communities declined slightly over the same period. We hypothesised that both program-related and non-program related factors were influencing the application behaviours of students.

This article starts by sketching the known factors which influence students' decision-making processes in their final years of schooling. We then describe the methodology and data sources of the larger study. The integrated results and discussion section focuses on the findings associated with program-related (or institutional) factors as well as the reported impact of widening participation programs on current and past participants. These shed light on the processes through which widening participation programs influence student behavior as well as the limits of these programs.

\section{Influences on Post-School Decision Making by School Students in Disadvantaged Communities}

There are multiple, often inter-related factors that have been identified as influencing students' decision-making processes about post-school options and which are being addressed by widening participation programs. Aspirations to attend university have been discussed prominently as a key factor following the release of the Australian Review of Higher Education in 2008 (Bradley et al., 2008). Educational aspiration has been defined as the desired level of education a student seeks to achieve (Reynolds \& Pemberton, 2001). It has been recognised that "there is no single determinant of education[al] aspirations, but rather a complex interplay between related considerations which operate cumulatively" (Regional Policy Advisory Committee 2013, p.32). Educational aspirations have been shown to be important influences impacting decisions to attend university 
(Johnston et al., 2014). Also key are parental expectations towards their child's participation in higher education, with differences observed by region, with families living in regional and remote areas recording substantially lower expectations than those in metropolitan areas, but less so by SES (Koshy et al., 2018).

While earlier research found that students from low SES backgrounds had lower aspirations for further education (James et al., 1999), more recent studies have suggested that aspirations for tertiary education are high and well established for students irrespective of SES (Gore et al., 2015; Prodonovich et al., 2014). What seems to be at play instead is the relative inability of young people from low SES or RRR backgrounds to maintain high aspirations over time (Gore et al., 2015), to translate aspirations into expectations to attend higher education (Vernon et al., 2018), or to convert aspirations into active participation at university (Hume Regional Development Australia, 2012).

There is an emerging literature which positions students' aspirations for higher education as separate from students' expectations to attend university (Guo et al. 2015; Watson et al., 2016). Vernon et al. (2018) and Cooper et al. (2017) found that students from regional areas were less likely to report an intention to study than metropolitan students. These recent studies encourage a change of focus from low aspirations as the determining factor of students' participation in higher education, to those factors which prevent young people in low SES or RRR communities from realising their high aspirations.

One conceptual framework that has been used to analyse potential enablers and barriers to participation, is Cross's (1981) model which was developed as an analytical tool to assess the factors which influenced decisions of mature learners. Cross identified institutional, situational and dispositional factors which influence students' decision to apply for university. The framework has been adopted by Carroll et al. (2009) as well as Jancey and Burns (2013) to explore postgraduate student participation in Australia. For our research, the focus is placed on school-leavers instead of adult learners and we explain the adaptations we have made to the model in the methodology.

\section{Methodology}

This study interrogated the impact of widening participation activities targeted at students in low SES schools and explored the factors, both program-related and external, that affect school-leaver applications to university. Data were collected from stakeholders using a mixed methods approach with two core components:

1. Quantitative analysis of Queensland school leaver university applications data, sourced at the school level, for all Queensland students from 2010 to 2016 as a proxy for student interest in university study.

2. Qualitative case study research comprising focus groups and interviews with:

a. school principals and staff $(n=15)$, current senior school students $(n=69)$, parents and community members $(n=33)$ in nine partner schools;

b. university outreach project managers $(n=14)$ from 8 universities; and

c. university students currently enrolled in a Consortium university $(n=46)$ who had previously attended a school targeted by widening participation interventions.

The schools were chosen based on their level of engagement with widening participation activities (moderate to high), their location (to provide a balance of urban and regional schools and representation across university partners) and their growth in university application rates (positive/negative). High engagement was defined as participation by most students in each cohort across all year levels for the duration of the project. Highly engaged schools participated in whole of cohort activities with multiple touch points which usually involved both on-campus and in-school activities. Engagement was assessed based on school engagement data provided by each university and university project managers were consulted on a shortlist of partner schools to approach. Data collection for the school case studies was conducted during Terms 2 and 3, 2017 (May to September) on school premises mostly during school hours.

Data from current university students were collected using a mix of focus groups and interviews to improve participation. Focus groups were around 60 minutes in duration and conducted at a campus of the partner university. Interviews were predominantly phone-based and were approximately 15-20 minutes in duration. All participants were recruited via email. Focus group and interview participants were provided with a monetry gift card in recognition of their time. 
Ethics approval was granted by the Curtin University Human Research Ethics Committee prior to data collection. Approval from the Queensland Department of Education was also obtained for collection of data in Queensland state schools.

\section{Quantitative Analysis}

The statistical analysis examined the influence of widening participation programs in Queensland in terms of the rate of applications to a Queensland Consortium university from schools targeted by widening participation interventions (WP schools) in comparison with other Queensland schools (non-WP schools), while controlling for a number of intervening variables. The study utilised university application data sourced from the Queensland Tertiary Admissions Centre (QTAC) as well as data on Year 12 completions sourced from the Queensland Curriculum and Assessment Authority (QCAA). The detailed design and analysis of the quantitative component of this study was undertaken by Paul Koshy and Ian Li and is documented in the full project report (Zacharias et al., 2018).

\section{Qualitative Analysis}

The aim of the qualitative component of this study was to assess the reported influence of widening participation activities in their context as well as the factors that were seen as enabling or preventing applications to university, and any perceived differential factors between RRR and urban areas. The data generated from university project managers and the school case studies were analysed together as their responses represented the two sides of the school-university partnerships. However, the current university student respondents were analysed separately to preserve the important post-facto perspective they brought to this study. Preliminary analyses of both sets of data were undertaken by two different single coders using an inductive (emergent) approach in the first instance. The case study data were analysed using an NVivo ${ }^{\text {TM }} 11$ project while the current student data were subject to manual thematic analysis.

\section{Analysis Framework}

The results of the two preliminary analysis processes were brought together at a project team meeting out of which a five-factor analysis framework was developed:

1. Institutional factors;

2. Situational factors;

3. Dispositional factors;

4. Impact of Consortium widening participation programs; and

5. Recommendations for optimising widening participation in regional settings.

With reference to Cross's (1981) model, a deductive approach was employed to map the sub-factors identified in the preliminary analyses. Consortium documents, including annual project reports and engagement data, were also used to verify program design, duration and engagement data for institutional factor analysis.

For this study, 'institutional' factors include all program-related factors, namely program design, degree of engagement by schools, funding levels and program implementation. Factors that affect students' participation in higher education but were beyond the control of the widening participation program were separated into 'situational' and 'dispositional' factors. Situational factors relate to the local school and wider community, the availability of role models and high-quality information as well as financial and other resource pressures. Dispositional factors capture beliefs, values and attitudes towards higher education study held by students and their key influencers as well as students' school achievement.

The impact factors were developed based on the themes which emerged in the preliminary analysis and by drawing on commonly reported objectives of widening participation programs. Any recommendations made by participants were collated under the fifth factor.

It was anticipated that the factors influencing school-leaver application rates would not necessarily separate neatly into distinct urban and regional sets of sub-factors, but that similar themes might emerge across all locations, but with potentially differential impacts. Thus, it was determined to measure how often a factor presented in the data (prominence) and how strongly - positive, 
neutral or negative - it was viewed by participants (sentiment). The concepts of prominence and sentiment are used frequently throughout the integrated results and discussion section.

\section{High Engagement Widening Participation Programs are Significantly Correlated with Application Rates}

The core finding of this study is that the widening participation program developed and implemented by the Queensland Consortium from 2011 are positively correlated with students' application rates to university, and that these correlations are statistically significant, but only in highly engaged schools. Our data suggest that Institutional and Impact factors together provide most explanation of the link between engagement in widening participation programs and changes in student application behavior. Thus, we briefly outline the results of the quantitative analysis before summarising and discussing the results related to Institutional and Impact factors. Detailed results are provided in appendices.

The modelling carried out for this study supported the general contention that region/regionality was important in explaining variations in the application rate between urban and RRR schools [refer to Table A in the Appendices]. There was a consistently lower level of application to universities from schools in regional and remote Queensland, even after introducing controls for socioeconomic variables in their local areas (IRSAD quartile). The inclusion of a richer series of explanatory variables allowed for an examination of the role of regionality and disadvantage in relation to school-level application rates. Once control variables for regional and socioeconomic disadvantage were included, as well as a variable representing academic pathways in Year 12 ((OP+IBD)/SEP), there was evidence that highly engaged widening participation programs have a positive correlation with application rates. Put differently, when measures of social and economic disadvantage and academic preparation were included in the model, the observed effect of the WP variable became positive and statistically significant in the case of highly engaged schools.

The analysis suggests that a comprehensive widening participation program which addresses most of the best-practice approaches identified by Gale et al. (2010) and Cupitt et al. (2016) and spans primary and secondary years (Fleming \& Grace, 2015; Gore et al., 2015), can positively influence the post-school choices of students from low SES backgrounds in favour of going to university. Our study demonstrates that the school is an appropriate unit of analysis in widening participation research because most interventions are targeted at the school level. At the same time, the school-level analysis imposes additional complexities in terms of sample size. In this study, the number of highly-engaged RRR schools was too small to demonstrate a significant effect at the regional level. In 2016, just 6 RRR schools met the highly engaged criteria. However, a positive effect was found for widening participation programs in highly engaged RRR schools which may emerge as significant in a larger sample.

While the results from the quantitative analysis demonstrate that highly engaged widening participation programs make a significant difference to university application rates from schools serving low SES communities, they cannot explain why; a dilemma previously observed by Passy and Morris (2010) in relation to the English Aimhigher program. We are drawing on the results of the qualitative component of this study, especially the nine school case studies, to demonstrate why and how highly engaged widening participation programs can influence application rates.

\section{Highly Engaged Widening Participation Programs are Resource-Intensive and Require Long-Term Investment}

The factors which underpin the positive relationships between highly engaged widening participation programs and application rates are best demonstrated by a comparison between the urban and RRR schools in this study. Although the Queensland widening participation program was designed so that RRR schools and students would get the same exposure to, and quality of, widening participation activities as their urban counterparts, our research suggests that this ambition was not fully realised and that it was a lot more difficult to achieve high levels of school engagement in RRR areas than urban ones. The analysis of institutional factors provides some insight as to why this might be the case.

Institutional factors, which related to program design and implementation, were both high in prominence and the source of several differentials in sentiment (please refer to Table B in the Appendices). The sub-factors which emerged as both differential and highly prominent were: 
- Duration and depth/intensity of widening participation program

- $\quad$ Intersection with marketing and other non-widening participation programs

- $\quad$ Strategic integration of widening participation program

Responses from project managers, and data held by the Queensland Consortium, show differences in the duration, depth and intensity of programs between RRR and urban areas. In urban areas, widening participation programs tended to have longer duration, greater intensity and reach, and were less affected by funding changes post-2014 than programs delivered in RRR locations. Table 1 shows that two urban universities (U3 and U5), had the largest number of school partnerships pre-HEPPP and were most successful in growing and sustaining school partnerships over time. In contrast, each of the regional universities had to undertake much greater development and scaling up of widening participation programs in the start-up phase of the Consortium project from late 2011 .

Table 1

Number of Schools Engaged in Widening Participation Activities by each Queensland University 2010, 2012,2014 and 2016

\begin{tabular}{|l|l|l|l|l|l|l|l|l|l|}
\cline { 2 - 10 } \multicolumn{1}{c|}{} & U1 & U2 & U3 & U4 & U5 & U6 & U7 & U8 & Total \\
\hline Regional Designation & Urban & Regional & Urban & Regional & Urban & Both & Regional & Regional & \\
\hline $\begin{array}{l}2010 \text { secondary school } \\
\text { engagement only }\end{array}$ & n/a & 11 & 16 & 6 & 16 & n/a & n/a & n/a & 49 \\
\hline $\begin{array}{l}2012 \text { primary and secondary } \\
\text { school engagement }\end{array}$ & 24 & 154 & 38 & 101 & 33 & 12 & 51 & 39 & 452 \\
\hline $\begin{array}{l}2014 \text { primary and secondary } \\
\text { school engagement }\end{array}$ & 29 & 169 & 40 & 115 & 33 & 15 & 105 & 43 & 549 \\
\hline $\begin{array}{l}2016 \text { primary and secondary } \\
\text { school engagement }\end{array}$ & 12 & 89 & 42 & 48 & 51 & 11 & 206 & 31 & 490 \\
\hline
\end{tabular}

In addition, the cluster approach of the Queensland Consortium model, where each university worked with a designated cluster or group of locally proximate schools, might have contributed to lower levels of engagement with RRR schools as it resulted in large differences in the number and geographic spread of schools across different clusters. While the grant phase (20112014) delivered funding based on the costs of provision, in the post-grant period cluster sizes were not adjusted and universities relied on their institutional HEPPP allocation to engage with schools which bore no relation to the costs of provision. Some universities had to manage significant reductions in funding post-2014. This was exacerbated by the change of the HEPPP allocation formula effective from 2015 in which the universal partnership allocation was discontinued and all HEPPP funding was awarded on the basis of the institution's low SES enrolment share.

The response across three of the four regional universities and two urban universities was to de-scale activities. Regional project managers reported difficulty in reaching all schools in their cluster due to the number of schools, their geographic dispersal and the cost of servicing them. Most regional university clusters were made up of a large number of schools spread over vast geographic regions. While some provincial city schools enjoyed easy access to their partner university, many RRR schools required extensive travel by land or air to reach. Regional project managers cited logistics, resourcing allocations and institutional priorities that mitigated against engagement with more remote schools in their regions. Program managers also reported that transport and accommodation costs in delivering programs to distant locations, or getting students from these locations to on-campus experiences, was a major factor in lower engagement in more remote locations. This finding stresses the complexity and cost of delivering effective widening participation programs across a vast geographic region which has previously been highlighted by Skene et al. (2016) in the Western Australian context.

Due to limited contact between RRR schools and universities, coupled with high staff turnover especially in remote schools, it was difficult to develop effective partnerships and fully integrate programs with school needs. Support by school leadership was generally strong across RRR and urban locations, however, this also suffered where engagement was more limited. School leaders reported alignment of widening participation and school objectives, but again in some RRR schools widening 
participation was more of an add-on than something that contributed meaningfully to school priorities. Only one RRR school in our sample reported a high level of widening participation integration.

In contrast, urban project managers had a smaller number of schools to service and all were relatively close to university campus locations. Urban universities were able to forge closer relationships with schools in their cluster and provide more ongoing contact. They were also much less constrained in facilitating on-campus experiences for school students and were usually able to provide these at no cost to the student participants. These findings were supported by the interviews with university students from regional backgrounds who mostly reported ad hoc widening participation programs while at school compared to more comprehensive and integrated experiences reported by students from urban locations.

The final section of the article will demonstrate how the differences in exposure to widening participation activities in urban versus RRR locations influenced students' decision-making processes around post-school options and introduce the concept of the virtuous circle of widening participation programs.

\section{A Virtuous Circle of Sustained Widening Participation Activity in Highly-Engaged Schools}

Differential impact factors for urban and RRR locations are displayed in Table C and Table D in the Appendix, with three factors emerging as highly prominent. These are:

- Demystifying university as a post-school option

- $\quad$ Changes in understanding of post-school options and pathways

- $\quad$ Specific widening participation activities that made a difference

However, the prominence of impact factors was consistently lower in RRR areas than urban ones across both samples in the qualitative analysis. We argue that the observed lower prominence of reported impact, particularly from remote schools, stems from the consistently lower exposure to widening participation activities in these locations, especially to on-campus experiences.

The analysis from the urban interviews and focus groups suggests that the sustained exposure to university as a desirable postschool option as well as first-hand experiences of university life through widening participation activities, especially on-campus visits and interactions with university ambassadors and staff, started a virtuous circle which led to more informed and confident decision making to pursue a specific course or pathway and, ultimately, higher enrolments at universities from these students. This is in line with the findings by Vernon et al. (2018) that students in regional areas need "concrete opportunities to support and develop their aspirations" over time so that student aspirations turn into an expectation to attend university after school (p.1). The steps in the virtuous circle are outlined in Figure 1. 


\section{Figure 1}

Virtuous Circle of Sustained Widening Participation Activity in Highly Engaged Schools
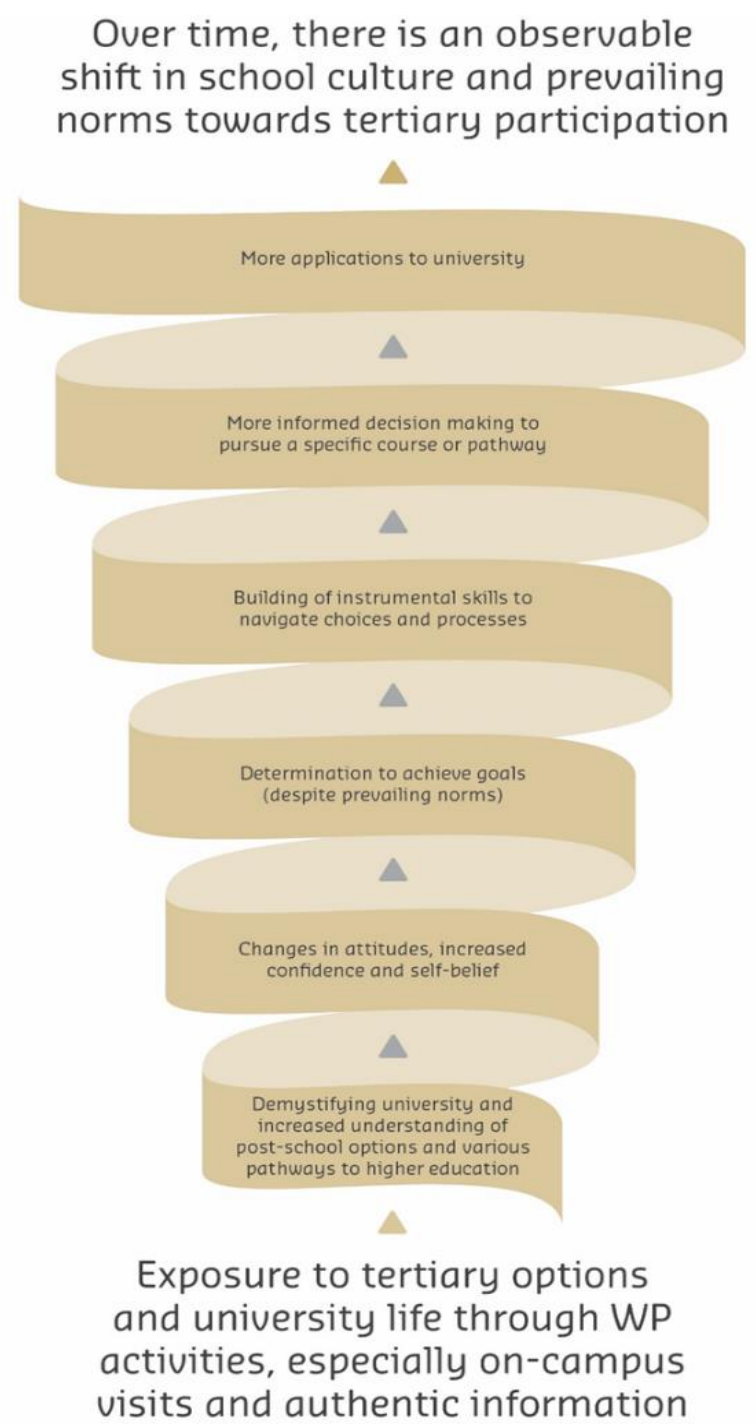

We propose that due to the lower levels of engagement with the widening participation program, the virtuous circle was not as strongly established in the RRR locations included in the sample and the impact of widening participation activities was more muted. The current university students interviewed for this study reported that widening participation in regional settings was typically ad hoc, sporadic, limited in variety of activities and often focused on larger, more popular university courses. Conversely, widening participation activities in urban settings were described as scheduled, regular, diverse, planned and strategically integrated into school activities.

While regional participants in the case study schools expressed similar sentiments about the benefits of widening participation activities to their urban counterparts, they had less opportunity to participate in those activities which led to less positive and more temporary effects throughout the circle and, ultimately, contributed to little change in application rates to university by students from RRR locations. This is congruent with the findings by Vernon et al. (2018) that the expectation to go to university declines with increasing distance from a major city. It seems that in the more distant locations, widening participation programs could not overcome the neighbourhood factors which acted as a barrier to university participation or, put differently, function as 'disrupters' (Webb et al., 2015) of traditional imaginations about the future. 


\section{Summary, Outlook and Recommendations}

This study provides empirical evidence through longitudinal data that widening participation programs are effective in increasing applications to university by school-leavers where the programs have been fully implemented and sustained at the school level resulting in highly engaged school-university partnerships. In the case of the Queensland Consortium, this outcome was generally achieved in urban areas and some provincial cities where ongoing partnerships with schools have been more easily established and maintained. Outcomes were less positive where insufficient resourcing and engagement levels led to the program not being delivered at scale and depth in all schools across the entire state, which was a more common issue in RRR schools than urban ones.

The concept of the virtuous circle of widening participation can illustrate the multi-layered influences of widening participation activities on student decision-making processes about post-school options. Where early and ongoing engagement between the school and a university did not occur, students could not readily distinguish between widening participation and marketing messages, aspirations to attend university did not translate into expectations to go, and the virtuous circle of widening participation activity did not manifest itself. The result was lower applications to university from those schools explaining, at least in part, the discrepancy in application rates between urban and RRR low SES schools.

This study adds to the existing evidence base that regional widening participation outreach work in Australia is expensive and resource intensive, and that institutional HEPPP allocations are insufficient to cover the costs of delivery into RRR areas. We recommend that tied funding be made available again through a dedicated partnership component of HEPPP to achieve full coverage of schools in RRR locations.

\section{References}

ACIL Allen Consulting (2017). Evaluation of the HEPPP. https://docs.education.gov.au/node/43911

Australian Department of Education, Employment and Workplace Relations [DEEWR] (2009), Transforming Australia's Higher Education System, Commonwealth of Australia: Canberra.

Bennett, A., Naylor, R., Mellor, K., Brett, M., Gore, J., Harvey, A., ... Whitty, G. (2015). The Critical Interventions Framework Part 2: Equity Initiatives in Australian Higher Education: A Review of Evidence of Impact. Canberra: Commonwealth of Australia.

Bradley, D., Noonan, R., Nugent, H., \& Scales, B. (2008). Review of Australian higher education: final report. https://www.voced.edu.au/content/ngv\%3A32134

Carroll, D., Ng, E., \& Birch, D. (2009). Retention and progression of postgraduate business students: An Australian perspective. Open Learning: The Journal of Open, Distance and e-Learning, 24(3), 197-209. https://doi.org/10.1080/02680510903201599

Cooper, G., Baglin, J., \& Strathdee, R. (2017). Access to higher education: Does distance impact students' intentions to attend university? National Centre for Student Equity in Higher Education (NCSEHE). https://www.ncsehe.edu.au/publications/access-to-higher-education-does-distance-impact-students-intentions-to-attenduniversity/

Cross, K.P. (1981). Adults as learners: Increasing participation and facilitating learning. Jossey-Bass.

Cupitt, C., Costello, D., Raciti, M., \& Eagle, L. (2016). Social marketing strategy for low SES communities: Position Paper (A report submitted to the Australian Government). National Centre for Student Equity in Higher Education (NCSEHE). https://www.ncsehe.edu.au/publications/social-marketing-strategy-low-ses-communities-position-paper/

Fleming, M. J., \& Grace, D. M. (2015). Increasing participation of rural and regional students in higher education. Journal of Higher Education Policy and Management, 36(5), 483-495. https://doi.org/10.1080/1360080X.2014.936089

Gale, T., Sellar, S., Parker, S., Hattam, R., Comber, B., Tranter, D., \& Bills, D. (2010). Interventions early in school as a means to improve higher education outcomes for disadvantaged (particularly low SES) students: A design and evaluation matrix for university outreach in schools. https://www.voced.edu.au/content/ngv\%3A43702

Gore, J., Holmes, K., Smith, M., Lyell, A., Ellis, H., \& Fray, L. (2015). Choosing university: The impact of schools and schooling. Teachers \& Teaching Research Program, The University of Newcastle. 
Guo, J., Parker, P. D., Marsh, H. W., \& Morin, A. J. S. (2015). Achievement, motivation, and educational choices: A longitudinal study of expectancy and value using a multiplicative perspective. Developmental Psychology, 51(8), 11631176. https://doi.org/10.1037/a0039440

Hume Regional Development Australia (2012). Aspirations and destinations of young people: A study of four towns and their communities and schools in Central Hume. University of Ballarat.

James, R., Wyn, J., Baldwin, G., Helpworth, G., McInnis, C., \& Stephanou, A. (1999). Rural and isolated school students and their higher education choices: a re-examination of student location, socio-economic background, and educational advantage and disadvantage (Commissioned Report No. 61). Centre for the Study of Higher Education and the Youth Research Centre. https://www.voced.edu.au/content/ngv\%3A42256

Jancey, J. \& Burns, S. (2013). Institutional factors and the postgraduate student experience. Quality Assurance in Education, 21(3), 311-322.

Johnston, D. W., Lee, W., Shah, C., Shields, M. A., \& Spinks, J. (2014). Are neighbourhood characteristics important in predicting the post-school destinations of young Australians? https://www.ncver.edu.au/research-andstatistics/publications/all-publications/are-neighbourhood-characteristics-important-in-predicting-the-post-schooldestinations-of-young-australians

Koshy, P. (2017). Briefing note: Equity student participation in Australian higher education: 2011 to 2016. National Centre for Student Equity in Higher Education (NCSEHE). https://www.ncsehe.edu.au/briefing-note-equity-studentparticipation-in-australian-higher-education-2011-to-2016/

Koshy, P., Dockery, A.M., \& Seymour, R. (2017). Parental expectations for young people's participation in higher education in Australia. Studies in Higher Education, 44(2), 302-317. https://doi.org/10.1080/03075079.2017.1363730

KPMG (2015). Evaluation of bridges to higher education: Final report. KPMG for Bridges to Higher Education Management Committee, University of Western Sydney.

Passy, R., \& Morris, M. (2010). Evaluation of Aimhigher: Learner attainment and progression (Final Report). National Foundation for Educational Research. https://www.voced.edu.au/content/ngv\%3A3458

Prodonovich, S., Perry, L. B., \& Taggart, A. (2014). Developing conceptual understandings of the capacity to aspire for higher education. Issues in Educational Research, 24(2), 174-189.

Regional Policy Advisory Committee (2013). Research into education aspiration for regional Victoria: Full report. https://apo.org.au/sites/default/files/resource-files/2013/01/apo-nid163331-1182286.pdf

Reynolds, J. R., \& Pemberton, J. (2001). Rising college expectations among youth in the United States: A comparison of the 1979 and 1997 NLSY. The Journal of Human Resources, 36(4), 703-726.

Skene, J., Pollard, L., \& House, H. (2016). Aspire UWA: A case study of widening access in higher education. Student Success, 7(2), 11-20. https://doi.org/10.5204/ssj.v7i2.337

Vernon, L., Watson, S. J., \& Taggart, A. (2018). University aspirational pathways for metropolitan and regional students: Implications for supporting school-university outreach partnerships. Australian and International Journal of Rural Education, 28(1), 87-103.

Watson, S. J., Vernon, L., Seddon, S., Andrews, Y., \& Wang, A. (2016). Parents influencing secondary students' university aspirations: A multilevel approach using school-SES. Issues in Educational Research, 26(4), 673-693.

Webb, S., Black, R., Morton, R., Plowright, S., \& Roy, R. (2015). Geographical and place dimensions of post-school participation in education and work. https://www.ncver.edu.au/research-and-statistics/publications/allpublications/geographical-and-place-dimensions-of-post-school-participation-in-education-and-work

Zacharias, N., Mitchell, G., Raciti, M., Koshy, P., Li, I., Costello, D., \& Trinidad, S. (2018). Widening Regional and Remote Participation: Interrogating the impact of outreach programs across Queensland. National Centre for Student Equity in Higher Education (NCSEHE). https://www.ncsehe.edu.au/publications/widening-regional-and-remote-participationinterrogating-the-impact-of-outreach-programs-across-queensland/ 


\section{Please cite this article as:}

Zacharias, N., \& Mitchell, G. (2020). The importance of highly engaged school-university partnerships in widening participation outreach. Student Success, 11(1), 35-45. https://doi.org/10.5204/ssj.v11i1.1458

This article has been peer reviewed and accepted for publication in Student Success. Please see the Editorial Policies under the 'About' section of the Journal website for further information.

Student Success: A journal exploring the experiences of students in tertiary education

(c) () free to use with proper attribution. ISSN: 2205-0795 